\title{
Application of New Appliances for Management of Growing Class III Malocclusion Child: Comparazation Case Reports
}

\author{
So-Youn $\mathrm{An}^{1}$, So-Young Park², Eun-Young Jeon ${ }^{3}$, and Youn-Soo Shim ${ }^{4, \dagger}$ \\ 'Department of Pediatric Dentistry, Wonkwang University College of Dentistry, Research Institute of Wonkwang \\ Bone Regeneration, Daejeon 35233, \\ ${ }^{2}$ Department of Dental Hygiene, Wonkwang Health Science University, Iksan 54538, \\ ${ }^{3}$ Department of Dental Hygiene, Kyungbok University, Namyangju 12051, \\ ${ }^{4}$ Department of Dental Hygiene, Sunmoon University, Asan 31460, Korea
}

\begin{abstract}
The purpose of this comparison of case reports is to introduce the results of the application of new devices for the management of growing Class III malocclusions in children. Two 8-year-old boys had a chief complaint of anterior crossbite. Anterior crossbite correction using a tandem traction bow appliance (TTBA) or a Carriere Motion 3D Class III appliance with a Transforce appliance was planned. By comparing cephalometric radiographs before and after treatment, changes in skeletal growth and incisor inclination to the Frankfort horizontal (FH) plane could be measured. Both devices increased SNA and ANB angles, N-| Pg-A, U1 to $\mathrm{SN}$, and $\mathrm{U} 1$ to $\mathrm{FH}$. Both appliances improved facial features and resolution of anterior crossbite. The TTBA and Carriere Motion 3D Class III appliance had similar effects when applied as early treatment for growing mesio-occlusions and anterior crossbite in two boys. However, long-term outcome assessments and well-designed comparative studies are still required.
\end{abstract}

Key Words: Anterior crossbite, Carriere Motion 3D Class III appliance, Mesio-occlusion, Tandem traction bow appliance

\section{Introduction}

A mesio-occlusion is a sagittal dentoalveolar relationship characterized by a forward position of the mandible compared to the upper and lower teeth ${ }^{1)}$. The previous classification, Angle III, is divided clinically into two types: the first type is either functional or pseudo III as the lower jaw is intermediately displaced, and the second type is truly skeletal III. Class III malocclusion occurs frequently in the Korean population, is easily recognized at an early age, and is often treated by pediatric dentistry at an early age ${ }^{2)}$. In pediatric dentistry, anterior crossbite in children is recommended for early treatment. Delaying treatment can result in a variety of complications, such as a reduced dental arch length, midline deviation, traumatic occlusion, wear of primary incisors, and restricted maxillary growth $^{3,4)}$. Up until now, the common clinical protocol for midfacial deficiency has been the use of a face mask using extraoral elastics, and its effect has been well-documented ${ }^{5,6}$. However, the main problems with this extraoral device are its appearance and high rate of complaints from patients.

On the other hand, a large number of intraoral devices have been introduced to treat class III malocclusions, including Fränkel's functional regulator ${ }^{7)}$, the reverse twin block $^{8)}$, and the modified tandem traction bow appliance (MTTBA $)^{9)}$. They do not have bulky external appearances or the potential for soft tissue irritation, which are associated with face mask therapy ${ }^{10)}$. The tandem traction bow appliance (TTBA) reported by Chun et al. ${ }^{11)}$ is an intraoral device consisting of an upper splint, a lower splint, and a traction bow. As the most recently developed device, the Carriere Motion 3D Class III appliance (Henry 
Schein Orthodontics, Carlsbad, CA, USA) is a fixed intraoral device consisting of a simple device attached to the buccal surface of the mandibular teeth (from the canine to the first permanent molar, or the first premolar to the first permanent molar) and a single tube-type orthodontic bracket attached to the upper first or secondary permanent molar using intraoral elastics (Force 1 and 2$)^{12}$.

The purpose of this comparison of cases is to introduce the results of the application of new devices for the management of growing Class III malocclusions in children. Furthermore, we evaluated the efficacy of these devices in comparison to face mask therapy. The study was conducted after approval by the research ethics committee of Wonkwang University in 2019. We received the patient's consent form about publishing all photographic materials.

\section{Case Reports}

\section{Case operation procedure}

The newly developed Carriere Motion 3D Class III device was compared using the dental and skeletal reference points and lines of the existing class III malocclusion treatment intraoral device, the TTBA. Photographs from lateral cephalometric radiography were taken before and after treatment and follow-up visits, and head measurements and analyses were made by one researcher using V-Ceph 8.0 (Osstem, Seoul, Korea). For the purpose of setting the measurement, 32 measuring points and 8 reference planes were selected and compared, referring to a number of clinically used analysis methods such as Steiner, Down, McNamara, and Rickets analysis.

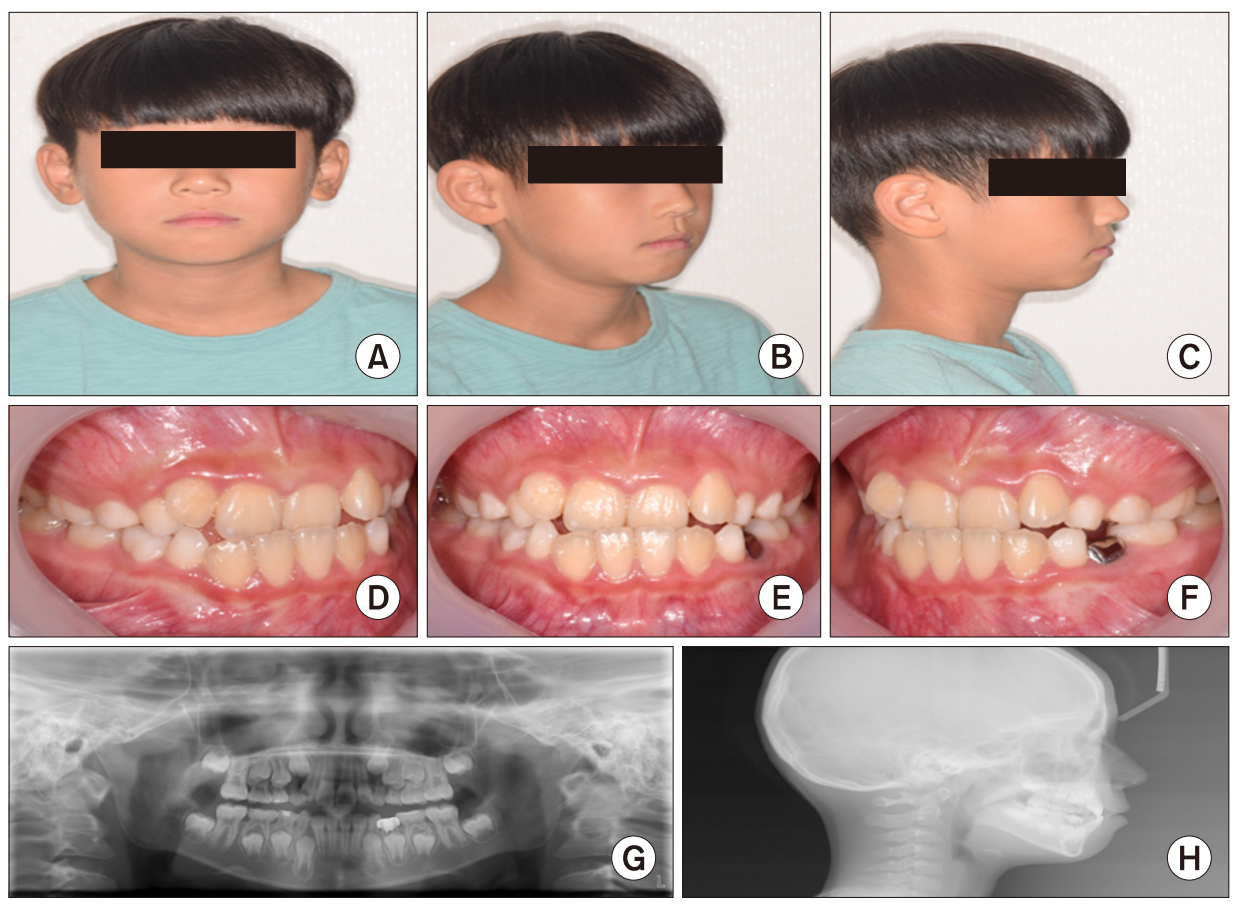

Fig. 1. $(A \sim C)$ Pre treatment extraoral photograph. (D F) Intraoral photograph. (G) Panoramic radiography. (H) Lateral cephalomeric radiography.
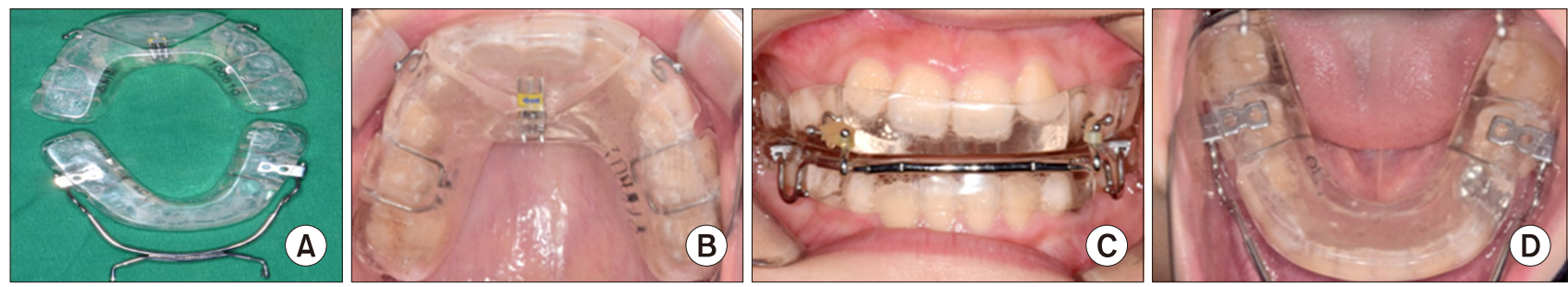

Fig. 2. (A) Delivery of the tandem traction bow appliance appliance to the patient. (B D) Post treatmentintraoral photograph. 


\section{Case 1}

An 8-year-old boy had a chief complaint of anterior crossbite. He also had concave facial features and Class III molar relationships (Fig. 1). Anterior crossbite correction using a TTBA (Fig. 2) was planned. The upper and lower portions were treated with extraoral elastics over a period of 14 hours a day. After achieving anterior crossbite correction, the TTBA was removed and treatment was considered complete. Growth had not yet ceased according to a hand wrist radiograph, and so we installed an EF ("éducation fonctionnelle", or Functional Education) appliance during the retention period. Comparing cephalometric radiographs from before and after treatment, changes in skeletal growth and incisor inclination to the
Frankfort horizontal (FH) plane could be measured (Fig, 3, Table 1). The patient gained improved facial features and resolution of anterior crossbite after treatment with a TTBA.

\section{Case 2}

An 8-year-old boy came to our clinic for orthodontic treatment. He had anterior crossbite and mild deficiency in the mid-facial area (Fig. 4). Anterior crossbite correction using a Carriere Motion 3D Class III appliance with a Transforce appliance (Fig. 5) was planned. We placed and welded the single tube on the buccal side and the lingual sheath on the lingual side of the orthodontic band, attached a band to the upper first permanent molar, and inserted the
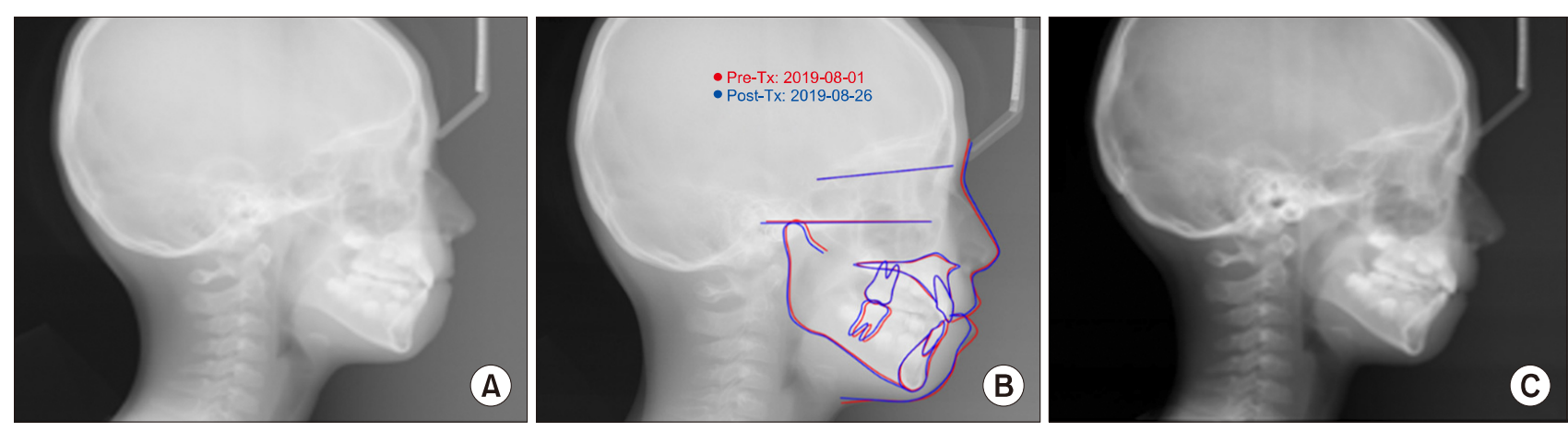

Fig. 3. (A) Post treatment lateral cephalomeric radiography. (B) Superimposition of pre and post treatment cephalograms. (C) Three months follow up; December 2019. Tx: treatment.

Table 1. Cephalometric Data of Case 1 (TTBA)

\begin{tabular}{|c|c|c|c|c|c|c|}
\hline Measurement & Mean & $\begin{array}{l}\text { Standard } \\
\text { deviation }\end{array}$ & $\begin{array}{c}\text { Pre-tx } \\
\left(1^{\text {th }} \text { Aug. 2019) }\right.\end{array}$ & $\begin{array}{c}\text { Post-tx } \\
\left(26^{\text {th }} \text { Aug. 2019) }\right.\end{array}$ & $\mathrm{p}<0.05$ & $\begin{array}{c}\text { Follow up } \\
\left(6^{\text {th }} \text { Dec. 2019) }\right.\end{array}$ \\
\hline FMA $\left(^{\circ}\right)$ & 26.00 & 3.00 & $31.68^{*}$ & 31.53 & & $\begin{array}{c}33.3 \\
\text { Normodivergent facial pattern }\end{array}$ \\
\hline SNA $\left({ }^{\circ}\right)$ & 81.00 & 3.00 & 79.45 & 80.12 & & 80.51 \\
\hline $\operatorname{SNB}\left({ }^{\circ}\right)$ & 78.00 & 3.00 & 76.54 & 76.66 & & 76.25 \\
\hline $\operatorname{ANB}\left({ }^{\circ}\right)$ & 3.68 & 2.00 & 2.91 & 3.90 & $\boldsymbol{\Delta}$ & 4.25 \\
\hline Wits appraisal $(\mathrm{mm})$ & -2.00 & 2.32 & -4.59 & -3.94 & $\boldsymbol{\Delta}$ & -2.15 \\
\hline A to N-perp (mm) & 0 & 1.00 & -3.37 & -2.85 & $\boldsymbol{\Delta}$ & $\begin{array}{l}\quad-2.61 \\
\text { Retruded maxilla }\end{array}$ \\
\hline Pog to N-perp (mm) & -0.50 & 1.00 & -12.88 & -12.81 & $\boldsymbol{\Delta}$ & -12.48 \\
\hline $\mathrm{U} 1$ to $\mathrm{SN}\left({ }^{\circ}\right)$ & 105.32 & 5.32 & 92.54 & 100.34 & $\boldsymbol{\Delta}$ & 102.05 \\
\hline $\mathrm{U} 1$ to $\mathrm{FH}\left({ }^{\circ}\right)$ & 116.00 & 5.50 & 99.87 & 107.09 & $\Delta$ & 105.99 \\
\hline $\operatorname{IMPA}\left({ }^{\circ}\right)$ & 95.65 & 4.65 & 91.90 & 92.02 & $\boldsymbol{\Delta}$ & 86.94 \\
\hline Overjet (mm) & 2.00 & 2.00 & 1.16 & 2.52 & $\boldsymbol{\Delta}$ & 2.98 \\
\hline Overbite (mm) & 2.00 & 2.00 & 1.18 & -0.25 & $\nabla$ & 0.17 \\
\hline
\end{tabular}

TTBA: tandem traction bow appliance, tx: treatment, FMA: Frankfort mandibular plane angle, SNA: sella-nasion-A point, SNB: sella-nasion-B point, ANB: A point-nasion-B point, FH: Frankfort horizontal, IMPA: lower incisor mandibular plane angle. ${ }^{*} \mathrm{p}<0.05$. 


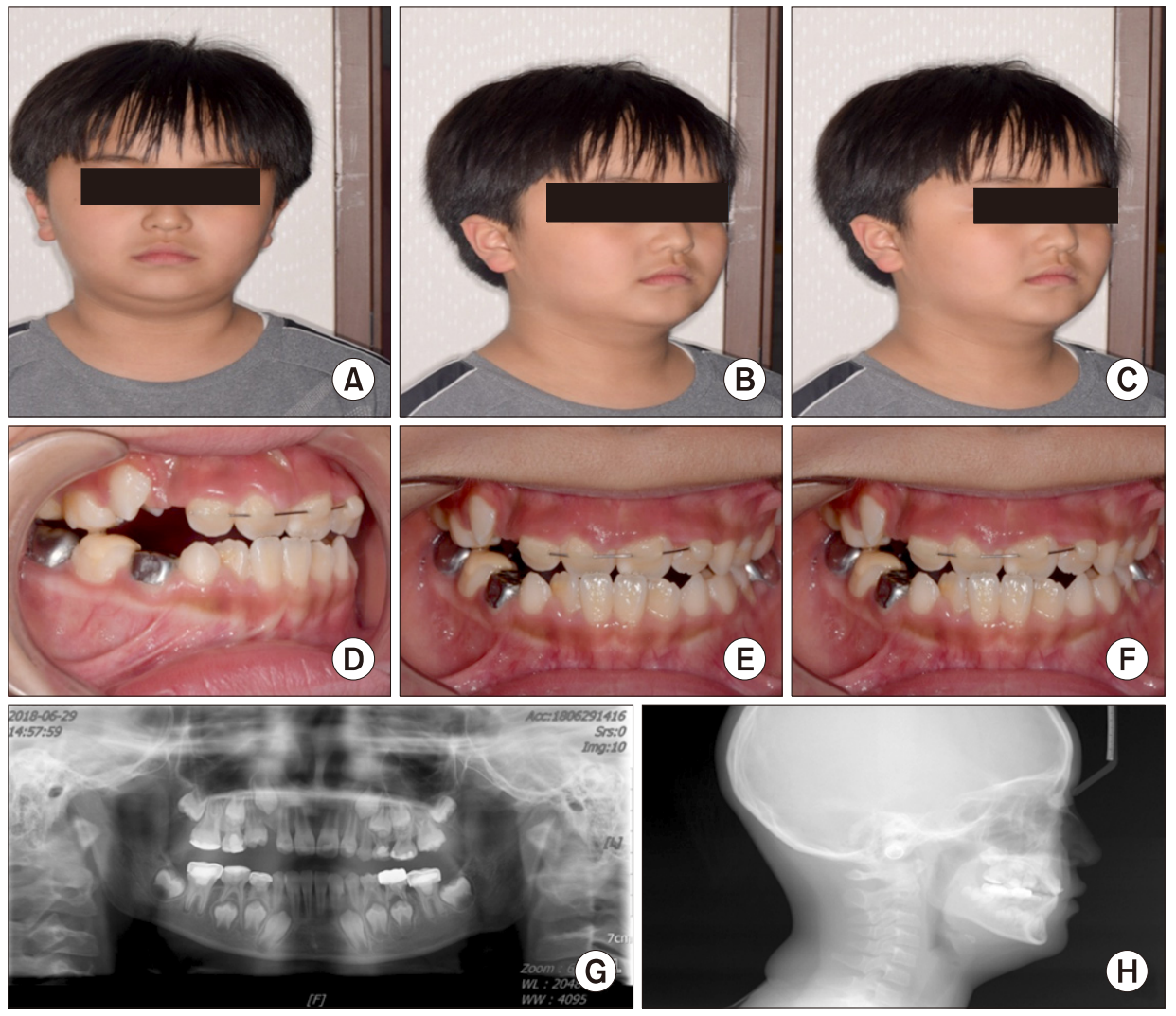

$\boldsymbol{H}$
Fig. 4. $(A \sim C)$ Pre treatment extraoral photograph. (D F) Intraoral photograph. (G) Panoramic radiography. (H) Lateral cephalomeric radiography.
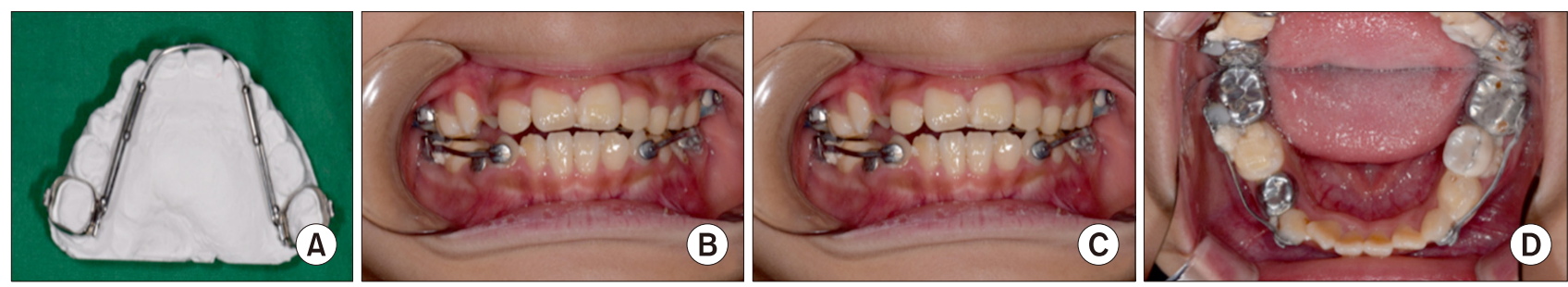

Fig. 5. (A) Delivery of the Carriere Motion 3D Class III appliance to the patient. (B D) Post treatmentintraoral photograph.

Transforce appliance on the lingual sheath. The Carriere Motion 3D Class III appliance was attached to the buccal surface of the mandibular teeth (from the canine to the first permanent molar) using Force 1 intraoral elastics for 3 months (24 hours a day) and Force 2 for 3 months (24 hours a day).

Comparing cephalometric radiographs before and after treatment, changes in skeletal growth and incisor inclination to the FH plane could be measured (Fig. 6, Table 2). The patient gained improved facial features and resolution of anterior crossbite after treatment with a Carriere Motion 3D Class III appliance.

\section{Discussion}

Two recent systematic reviews of early treatment of class III malocclusions focused on comparing groups treated with different types of instruments to an untreated control group ${ }^{13,14)}$. In general, face masks are the most widely used orthopedic devices to treat developing patients with a maxillary deficiency as they have a relatively short-term application that is good for skeletal and dental purposes ${ }^{15)}$. However, the downsides are reduction of the mandibular teeth due to pressure from the chin cup and the overall appearance of the mask across the face. These 

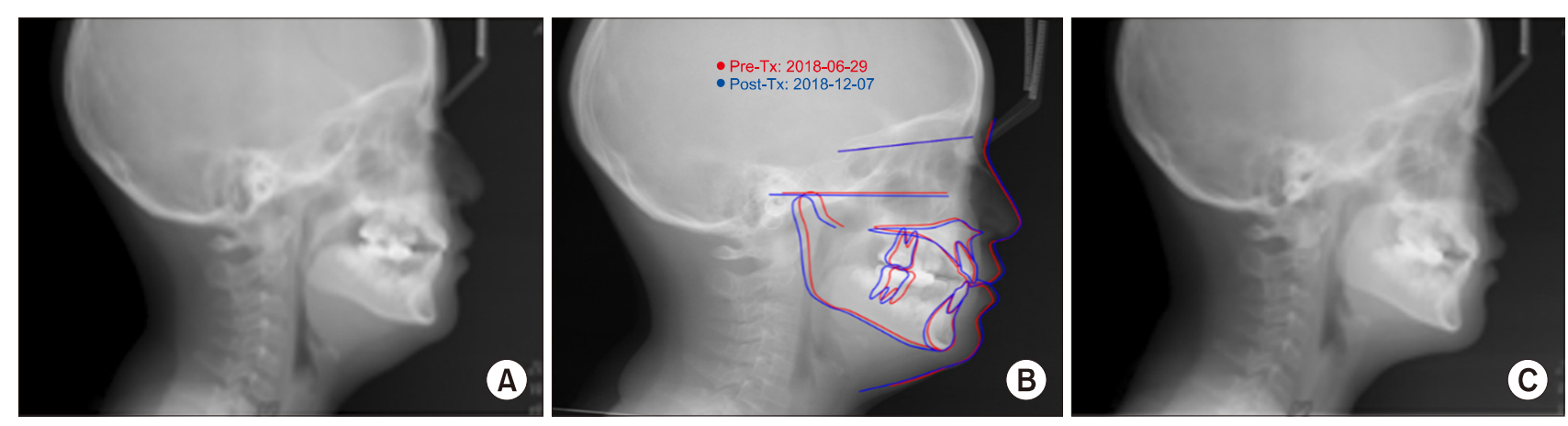

Fig. 6. (A) Post treatment lateral cephalomeric radiography. (B) Superimposition of pre and post treatment cephalograms. (C) Three months follow up; March 2019.

Table 2. Cephalometric Data of Case 2 (Carriere motion 3D III)

\begin{tabular}{|c|c|c|c|c|c|c|}
\hline Measurement & Mean & $\begin{array}{l}\text { Standard } \\
\text { deviation }\end{array}$ & $\begin{array}{c}\text { Pre-tx } \\
\left(29^{\text {th }} \text { Jun 2018) }\right.\end{array}$ & $\begin{array}{c}\text { Post-tx } \\
\left(7^{\text {th }} \text { Dec 2018) }\right.\end{array}$ & $\mathrm{p}<0.05$ & $\begin{array}{c}\text { Follow up } \\
\text { (15th Mar 2019) }\end{array}$ \\
\hline FMA $\left({ }^{\circ}\right)$ & 30.32 & 2.1 & $24.91^{*}$ & $24.61 *$ & & $\begin{array}{c}25.45^{*} \\
\text { Hypodivergent facial pattern }\end{array}$ \\
\hline SNA $\left({ }^{\circ}\right)$ & 79.46 & 3.3 & 80.33 & 82.56 & & 80.99 \\
\hline $\operatorname{SNB}\left({ }^{\circ}\right)$ & 75.86 & 2.8 & 77.41 & 78.55 & & 77.89 \\
\hline $\operatorname{ANB}\left({ }^{\circ}\right)$ & 3.60 & 1.2 & 2.91 & 4.01 & $\Delta$ & 3.10 \\
\hline Wits appraisal (mm) & -2.24 & 0.3 & $-3.04 *$ & $-1.34 * * *$ & $\Delta$ & -2.15 \\
\hline A to N-perp (mm) & 1.10 & 2.7 & -2.40 & -0.46 & $\Delta$ & $\begin{array}{l}\quad-2.28 \\
\text { Retruded maxilla }\end{array}$ \\
\hline Pog to N-perp (mm) & -0.30 & 2.5 & $-8.33 * * *$ & $-7.65^{*}$ & $\Delta$ & $-8.21 * * *$ \\
\hline $\mathrm{U} 1$ to $\mathrm{SN}\left({ }^{\circ}\right)$ & 101.94 & 4.4 & 98.28 & 102.26 & $\Delta$ & 103.81 \\
\hline $\mathrm{U} 1$ to $\mathrm{FH}\left({ }^{\circ}\right)$ & 108.70 & 4.0 & 105.59 & 109.23 & $\Delta$ & 110.63 \\
\hline IMPA $\left({ }^{\circ}\right)$ & 91.46 & 3.4 & 87.93 & 93.74 & $\Delta$ & 91.53 \\
\hline Overjet (mm) & 2.00 & 2.0 & 1.90 & 2.99 & $\Delta$ & 3.72 \\
\hline Overbite (mm) & 2.00 & 2.0 & 1.64 & 0.52 & $\nabla$ & 0.69 \\
\hline
\end{tabular}

tx: treatment, FMA: Frankfort mandibular plane angle, SNA: sella-nasion-Apoint, SNB: sella-nasion-B point, ANB: A point-nasion-B point, FH: Frankfort horizontal, IMPA: lower incisor mandibular plane angle.

${ }^{*} \mathrm{p}<0.05,{ }^{* * *} \mathrm{p}<0.001$.

factors can compromise patient compliance and affect therapeutic results ${ }^{16-18)}$. In a study comparing patients with a MTTBA or a Delaire-type face mask with non-treatment groups during an 11-month period, Tortop et al. ${ }^{9)}$ reported that both types of devices had satisfactory skeletal and dentoalveolar improvements compared to the control groups. The increase in the ANB angle in the face mask group was significantly greater than in the MTTBA group. Husson et al. ${ }^{19)}$ designed a face mask with upper jaw expansion using rapid maxillary expansion and compared it to TTBAs in a randomized controlled trial and found that the degree of extrusion of the mandibular molars was superior with a TTBA and the degree of intrusion of the mandibular incisors was superior with the face mask, but the front movement of the upper dental arch was similar in both devices. Both the TTBA and the face mask groups were effective in treating class III malocclusion. The TTBA group was more efficient in controlling clockwise rotation and gaining space in the lower $\operatorname{arch}^{19}$.

Fixed intraoral appliances also eliminate patient compliance issues. Although these new devices have been growing in popularity among clinical practitioners over the last decade, few studies are available to evaluate the treatment efficiency of Class III correction. The Carriere Motion 3D Class III appliance has been marketed as a Class III corrector that functions by rotating and righting the 
mandibular first molars while pushing back the posterior segments as a unit ${ }^{20)}$. The upper arch, either banded with an upper lingual holding arch (e.g., a Transforce appliance) or held together with a clear retainer, serves as the main anchor point for Class III correction (Fig. 5). Depending on the span of the Carriere Motion 3D Class III device, elastics can be worn from the lower canines or premolars to the lower molars; these are similar to Class III intermaxillary elastics. Our results show that both devices increased the SNA angle, ANB angle, $\mathrm{N}-\mid \mathrm{Pg}-\mathrm{A}, \mathrm{U} 1$ to $\mathrm{SN}$, and U1 to FH. Since a literature search showed little comparison between the Carriere Motion 3D Class III fixed device and the existing device applied for Class III malocclusion, we would like to use our comparison as the basis for designing future experimental designs through a comparative analysis of two examples similar in sex and age.

In conclusion, TTBA and Carriere Motion 3D Class III appliance had similar effects when applied to early treatment of Mesio-occlusion and anterior crosstie growing child. However, long-term outcome assessments and well-designed comparative studies are expected to be required.

\section{Notes}

\section{Conflict of interest}

No potential conflict of interest relevant to this article was reported.

\section{Ethical approval}

This study was approved by the institutional review board of Wonkwang University Hospital (IRB No. W1910/001-001).

\section{Author contributions}

Conceptualization: Youn-Soo Shim, So-Youn An. Data acquisition: So-Youn An. Formal analysis: Eun-Young Jeon. Supervision: Youn-Soo Shim. Writing-original draft: Youn-Soo Shim, So-Youn An. Writing-review \& editing: So-Young Park, Eun-Young Jeon.

\section{ORCID}

So-Youn An, https://orcid.org/0000-0002-8395-7881

So-Young Park, https://orcid.org/0000-0002-6646-0785
Eun-Young Jeon, https://orcid.org/0000-0002-0699-2202

Youn-Soo Shim, https://orcid.org/0000-0002-2894-2441

\section{Acknowledgements}

None.

\section{References}

1. Nakasima A, Ichinose M, Nakata S: Genetic and environmental factors in the development of so-called pseudo- and true mesiocclusions. Am J Orthod Dentofacial Orthop 90: 106-116, 1986. https://doi.org/10.1016/0889-5406(86)90041-7

2. Lee SH: Diagnosis and treatment of Class III malocclusion in children. J Korean Acad Pediatr Dent 34: 725-740, 2007.

3. Kapur A, Chawla HS, Utreja A, Goyal A: Early class III occlusal tendency in children and its selective management. J Indian Soc Pedod Prev Dent 26: 107-113, 2008. https://doi.org/10.4103/0970-4388.43191

4. Campbell PM: The dilemma of Class III treatment. Early or late? Angle Orthod 53: 175-191, 1983.

5. Toffol LD, Pavoni C, Baccetti T, Franchi L, Cozza P: Orthopedic treatment outcomes in class III malocclusion. A systematic review. Angle Orthod 78: 561-573, 2008. https://doi.org/10.2319/030207-108.1

6. Fudalej P, Dragan M, Wedrychowska-Szulc B: Prediction of the outcome of orthodontic treatment of Class III malocclusions--a systematic review. Eur J Orthod 33: 190-197, 2011. https://doi.org/10.1093/ejo/cjq052

7. Baik HS, Jee SH, Lee KJ, Oh TK: Treatment effects of Fränkel functional regulator III in children with class III malocclusions. Am J Orthod Dentofacial Orthop 125: 294-301, 2004.

https://doi.org/10.1016/j.ajodo.2003.04.016

8. Minase RA, Bhad WA, Doshi UH: Effectiveness of reverse twin block with lip pads-RME and face mask with RME in the early treatment of class III malocclusion. Prog Orthod 20: 14, 2019. https://doi.org/10.1186/s40510-019-0266-0

9. Tortop T, Kaygisiz E, Gencer D, Yuksel S, Atalay Z: Modified tandem traction bow appliance compared with facemask therapy in treating Class III malocclusions. Angle Orthod 84: 642-648, 2014. 
https://doi.org/10.2319/080513-584.1

10. Showkatbakhsh R, Jamilian A, Ghassemi M, Ghassemi A, Taban T, Imani Z: The effects of facemask and reverse chin cup on maxillary deficient patients. J Orthod 39: 95-101, 2012. https://doi.org/10.1179/1465312512Z.00000000011

11. Chun YS, Jeong SG, Row J, Yang SJ: A new appliance for orthopedic correction of Class III malocclusion. J Clin Orthod 33: 705-710, 1999.

12. Carrière L: A new Class II distalizer. J Clin Orthod 38: 224-231, 2004.

13. Thiruvenkatachari B, Harrison JE, Worthington HV, O'Brien KD: Orthodontic treatment for prominent upper front teeth (Class II malocclusion) in children. Cochrane Database Syst Rev (11): CD003452, 2013. https://doi.org/10.1002/14651858.CD003452.pub3

14. Woon SC, Thiruvenkatachari B: Early orthodontic treatment for Class III malocclusion: a systematic review and metaanalysis. Am J Orthod Dentofacial Orthop 151: 28-52, 2017. https://doi.org/10.1016/j.ajodo.2016.07.017

15. Seehra J, Fleming PS, Mandall N, Dibiase AT: A comparison of two different techniques for early correction of Class III malocclusion. Angle Orthod 82: 96-101, 2012.

https://doi.org/10.2319/032011-197.1

16. Chong YH, Ive JC, Artun J: Changes following the use of protraction headgear for early correction of Class III malocclusion. Angle Orthod 66: 351-362, 1996.

17. Kim JH, Viana MA, Graber TM, Omerza FF, BeGole EA: The effectiveness of protraction face mask therapy: a metaanalysis. Am J Orthod Dentofacial Orthop 115: 675-685, 1999. https://doi.org/10.1016/s0889-5406(99)70294-5

18. Azamian Z, Shirban F: Treatment options for Class III malocclusion in growing patients with emphasis on maxillary protraction. Scientifica (Cairo) 2016: 8105163, 2016. https://doi.org/10.1155/2016/8105163

19. Husson AH, Burhan AS, Salma FB, Nawaya FR: Dentoskeletal effects of the modified tandem appliance vs the facemask appliance in the treatment of skeletal class III malocclusion: a single-center, randomized controlled trial. J Contemp Dent Pract 17: 522-529, 2016. https://doi.org/10.5005/jp-journals-10024-1883

20. Carriére L: Nonsurgical correction of severe skeletal Class III malocclusion. J Clin Orthod 50: 216-230, 2016. 